\title{
Lotion deodorant formulation of ethanolic extract of red betel leaf (Piper crocatum Ruiz \& Pav) with stearic acid as base
}

\section{Formulasi sediaan losion deodoran ekstrak etanolik daun sirih merah (Dasimer) (Piper crocatum Ruiz \& Pav) berbasis asam stearat}

\author{
Lidia $^{1 *}$, Ensiwi Munarsih1ㅜ, Dini Aprilianti ${ }^{1}$ \\ ${ }^{1}$ Sekolah Tinggi Ilmu Farmasi Bhakti Pertiwi \\ *Corresponding author: lidia.kopertis@gmail.com
}

\begin{abstract}
Background: Red betel leaf (P. crocatum Ruiz \& Pav) possesses antibacterial properties, so the prospect is to be developed as a deodorant in lotion dosage forms.

Objective: This study was conducted with the intention to prepare, evaluate, and investigate the stability of deodorant lotion preparations from the ethanolic extract of red betel leaf ( $P$. crocatum Ruiz \& Pav) based on stearic acid.

Methods: The maceration method used $70 \%$ ethanol as solvent to obtain red betel leaf extract. Furthermore, the concentrated extract was formulated as a deodorant lotion formula into three formulas, FI, FII, and FIII, with varying concentrations of stearic acid 2,4 , and $6 \%$, respectively. All the deodorant lotion formulas were evaluated, their characteristics and stability of organoleptic, pH, homogeneity, viscosity, spreadability, adhesion, and irritation properties. The physical stability test was done by cycling test. The storage stability test was evaluated for 28 days.

Results: Evaluation of physical properties for 28 days showed that deodorant lotion was homogeneous and $\mathrm{pH}$ in the range of 5.5-6.4; viscosity, spreadability, and adhesion tests gave good results and stability. In the irritation test, all formulas showed no irritation. Statistical test paired T-test on stability testing during storage and cycling test showed that the best and most stable formula was F3 with 6\% stearic acid concentration.

Conclusion: Ethanolic extract of red betel leaf (P. crocatum Ruiz \& Pav) can be formulated into a deodorant lotion preparation that is stable and good during storage.

Keywords: deodorant lotion, Piper crocatum Ruiz \& Pav, stearic acid

\section{Intisari}

Latar belakang: Daun sirih merah (Dasimer) (P. crocatum Ruiz \& Pav) berkhasiat sebagai antibakteri, sehingga prospek untuk dikembangkan sebagai deodorant dalam bentuk sediaan losion.

Tujuan: Penelitian ini dilakukan dengan tujuan untuk membuat, mengevaluasi dan melakukan uji stabilitas sediaan losion deodoran dari ekstrak etanol Dasimer (P. crocatum Ruiz \& Pav) dengan variasi basis asam sterat.

Metode: Ekstrak Dasimer diekstraksi menggunakan metode maserasi dengan etanol 70\% sebagai pelarut. Ekstrak kental etanol yang diperoleh diformulasikann menjadi 3 formula losion yaitu FI, FII dan FIII dengan variasi asam stearate 2, 4 dan $6 \%$. Formula losion deodoran, dievaluasi karakteristik dan stabilitasnya meliputi organoleptis, homogenitas, $\mathrm{pH}$, viskositas, daya sebar, daya lekat dan iritasi. Uji stabilitas fisik dilakukan dengan cycling test. Uji stabilitas dalam penyimpanan dievaluasi selama 28 hari.

Hasil: Evaluasi sifat fisik selama 28 hari menunjukkan bahwa deodoran losion homogen dan $\mathrm{pH}$ dalam rentang yang baik yakni 5,5-6,4. Pengujian viskositas, daya sebar dan daya lekat juga memberikan hasil yang baik dan stabil. Pada pengujian iritasi, semua formula menunjukkan tidak terjadi iritasi. Uji statitistik T-test
\end{abstract}


berpasangan pada pengujian stabilitas selama penyimpanan dan cycling test, menunjukkan bahwa formula yang paling baik dan stabil yaitu F3 dengan konsentrasi asam stearat $6 \%$.

Kesimpulan: Ekstrak etanol Dasimer (P. crocatum Ruiz \& Pav) dapat dibuat menjadi sediaan deodoran losion yang stabil dan baik pada saat penyimpanan.

Kata Kunci: losion deodoran, Piper crocatum Ruiz \& Pav, asam stearat

\section{Pendahuluan}

Kosmetik adalah bahan atau sediaan yang ditujukan untuk penggunaan bagian luar tubuh manusia yakni epidermis, kuku, bibir, rambut dan termasuk juga organ genital bagian luar, gigi dan juga mukosa mulut. Fungsi utama untuk membersihkan, mewangikan, mengubah penampilan dan atau memperbaiki bau badan atau pun melindungi atau memelihara tubuh tetap pada kondisi yang baik (MenKes RI, 2010).

Deodoran merupakan salah satu bentuk sediaan kosmetika yang penggunaannya ditujukan untuk mengatasi bau badan yang disebabkan oleh keringat yang apabila bercampur dengan bakteri dapat menyebakan bau badan. Beberapa bakteri yang diduga menjadi penyebab bau badan yaitu Staphylococcus epidermidis, Pseudomonas aerugenos, Corybacterium acne, Pseudomonas aerugino, Streptococcus pyogenes serta Staphylococcus aureus (Lailiyah dkk, 2019). Secara komersial deodoran yang telah beredar dipasaran mempunyai beberapa bentuk seperti bentuk sediaan cair, batang, cream, jeli, serbuk, losion, dan bentuk aerosol (Agoes, 2015).

Meninjau dengan banyaknya efek samping yang diakibatkan oleh penggunaan deodoran yang telah beredar di pasar seperti halnya iritasi pada kulit ketiak, oleh karena itu perlu bahan baku deodoran yang lebih aman yakni dengan memanfatkan bahan alami. Tanaman Dasimer dengan nama ilmiah P. crocatum Ruiz \& Pav adalah satu di antara beberapa tanaman yang memiliki khasiat sebagai antibakteri sehingga dapat dipilih menjadi bahan aktif deodoran karena kefektifannya sebagai antibakteri dan sekaligus mengatasi bau badan (Umami, 2019).

Adapun senyawa kimia yang ada dalam Dasimer adalah alkaloid, triterpenoid, flavonoid, tanin, saponin, minyak atsiri (Umami, 2019) serta untuk ekstrak etanol Dasimer (P. crocatum Ruiz \& Pav) dapat menghambat bakteri pertumbuhan Staphylococcus aureus (Candrasari dkk, 2012).

Dari latar belakang tersebut, maka dilakukanlah penelitian mengenai formulasi losion deodoran ekstrak etanol Dasimer (P. crocatum Ruiz \& Pav) dengan menggunakan variasi basis asam stearat.

Seminar Nasional Asosiasi Perguruan Tinggi Farmasi Indonesia (APTFI) III-Tantangan Pandemik (covid-19) dalam pembelajaran dan penelitian kefarmasian 16-20 Agustus 2021 (Virtual Conference) 


\section{Metode}

\subsection{Bahan}

Bahan-bahan yang digunakan dalam penelitian ini adalah antara lain, Dasimer, asam stearat, alfa tokoferol, setil alkohol, trietonolamin, metil paraben, propil paraben, gliserin, minyak esensial lemon, akuades, etanol 70\%, kertas saring.

\subsection{Pengambilan sampel tanaman}

Tumbuhan sirih merah didapatkan dari Desa Beringin, Kecamatan Lubai, Kabupaten Muara Enim.

\subsection{Proses pembuatan ekstrak}

Ekstraksi Dasimer dilakukan dengan cara merendam simplisia dengan etanol 70\% selama 5 hari dengan 3 kali pengulangan, sambil sesekali di aduk setiap hari. Hasil maserasi yang diperoleh dipekatkan menggunakan rotari evaporator.

\subsection{Formulasi dan pembuatan losion deodoran}

Komposisi formula losion deodoran dari ekstrak Dasimer tersaji pada Tabel 1.

Tabel 1. Orientasi formulasi losion deodoran Dasimer (100 g)

\begin{tabular}{llll}
\hline \multirow{2}{*}{ Bahan $(\mathrm{g})$} & \multicolumn{3}{c}{ Jumlah bahan } \\
\cline { 2 - 4 } & FI & FII & FIII \\
\hline Ekstrak etanol sirih merah & 7,5 & 7,5 & 7,5 \\
Asam stearate & 2 & 4 & 6 \\
Alfa tokoferol & 0,05 & 0,05 & 0,05 \\
Setil alkohol & 3 & 3 & 3 \\
Trietonolamine & 3 & 3 & 3 \\
Metil paraben & 0,1 & 0,1 & 0,1 \\
Propil paraben & 0,1 & 0,1 & 0,1 \\
Gliserin & 10 & 10 & 10 \\
Minyak essensial lemon & 0,7 & 0,7 & 0,7 \\
Akuades ad & 100 & 100 & 100 \\
\hline
\end{tabular}

Fase air dibuat dengan cara memanaskan akuades di atas waterbath setelah panas dimasukkan metil paraben hingga larut, kemudian dimasukan TEA berurutan dengan gliserin, dan diaduk sampai homogen. Fase minyak yakni setil alkohol, propil paraben dan asam stearat ditempatkan pada wadah terpisah, dipanaskan diatas waterbath pada suhu mencapai $70^{\circ} \mathrm{C}$. Fase minyak ditambahkan ke fase air kemudian dihomogenkan dengan menggunakan homogenizer. Selanjutnya, ekstrak etanol Dasimer ditambahkan sedikit demi sedikit, alfa tokoferol dan minyak esensial lemon hingga tercampur homogen. Kemudian dikemas dan dimasukkan ke dalam wadah yang sesuai. 


\subsection{Pengujian stabilitas formula}

Seluruh pengujian stabilitas pada masa penyimpanan dilakukan pada ketiga formula yakni FI, FII dan FIII. Periode penyimpanan selama 28 dan pengujian sampel dilakukan pada hari ke ke-0, ke-7, -14, -21 dan -28.

\subsubsection{Uji organoleptis}

Uji organoleptik dilakukan dengan cara sebagai berikut, sejumlah sampel dari masingmasing formula losion deodorant ekstrak etanol Dasimer (F2, F2 dan F3), diperiksa tekstur, bau, dan perubahan warnanya selama masa penyimpanan 28 hari. Hasil pengmatan bisa diambil gambarnya dan dicatat (Ervianingsih \& Razak, 2019).

\subsubsection{Uji homogenitas}

Uji homogenitas dapat dilakukan dengan mengambil sediaan losion deodoran kemudian diletakkan di atas kaca objek, lalu diratakan dengan menggunakan kaca objek lainnya. Kemudian diamati, apakah terlihat adanya partikel-partikel kasar pada sediaan, lalu dicatat hasilnya (bila perlu diambil gambarnya) selama masa penyimpanan (Ervianingsih \& Razak, 2019).

\subsection{3. $U j i \mathrm{pH}$}

Uji pH dilakukan dengan cara sebagai berikut, sampel losion deodoran ditimbang kurang lebih 1 gram. Sampel dimasukkan ke dalam gelas kimia kemudian dilarutkan dengan aquadest. Setelah itu dimasukkan elektroda kedalam gelas kimia yang berisi sampel uji hingga nilai pH pada layar. Hasil pengujian $\mathrm{pH}$ dicatat dan diamati perubahan pH-nya selama masa penyimpanan (Erviangsih \& Razak, 2019).

\subsubsection{Uji viskositas}

Sejumlah sampel (FI, FII dan FIII) dimasukkan dalam cup pada viscometer Brookfield, kemudian spindle ukuran 4 dipasang dan rotor dijalankan dengan kecepatan $60 \mathrm{rpm}$. Nilai viskositas yang tertera pada layar dikalikan dengan faktor koreksi 200 (Timur dkk, 2019). Kisaran nilai viskositas yang dipersyaratkan yaitu berada dalam kisaran nilai 2000-8000 cPs (centipoise) (Daud dkk, 2018).

\subsubsection{Uji daya sebar}

Pengujian daya sebar dilakukan dengan cra sebagai berikut, sampel losion ditimbang sebesar 0,5 gram dan diletakkan di tengah kaca bulat. Kaca bulat lainnya diletakkan di atas sediaan dan beri beban 125 gram. Lalu diamkan selama 1 menit, kemudian diameter penyebarannya diukur dan dicatat. Daya sebar losion yang baik itu bila berada di kisaran 5-7 cm (Mardikasari dkk, 2017). 


\subsubsection{Uji daya lekat}

Uji daya lekat dilakukan dengan cara sebagai berikut, sebanyak 0,25 gram sediaan losion ditimbang, lalu diletakkan dititik tengah luasan objek gelas yang telah tandai dan ditutup dengan objek gelas lain. Kemudian diberi beban 100 gram selama 5 menit lalu kedua objek gelas yang telah saling melekat 1 sama lain dipasang pada alat uji yang diberi beban 80 gram. Setelah itu dicatat waktu yang diperlukan hingga terpisah 2 objek gelas tersebut. Pengujian dilakukan selama masa penyimpanan (Megantara dkk, 2017).

\subsection{Cycling test}

Uji kestabilan sediaan pada cycling test ini dilakukan dengan cara sebagai berikut, sediaan deodoran disimpan di dalam suhu $4^{\circ} \mathrm{C}$ selama 24 jam kemudian dipindahkan ke suhu $40^{\circ} \mathrm{C}$ selama 24 jam, siklus ini dihitung sebagai satu siklus. Pengujian stabilitas pada $\mathrm{pH}$ dan viskositas ini dilakukan sebanyak 6 siklus (Sari, 2019).

\subsection{Uji iritasi}

Pengujian ini dilakukan pada 10 orang sukarelawan terhadap masing-masing formula dari sediaan. Losion sebanyak 0,1-0,5 gram dioleskan dibelakang telinga kemudian dibiarkan selama 24 jam setelah itu dilakukan pengamatan dan dicatat hasil pengamatannya (Wasitaatmadja, 1997).

\subsection{Analisa data}

Data yang diperoleh berupa hasil pengamatan dari segi fisik meliputi data organoleptis, pH, viskositas, homogenitas, daya sebar, daya lekat, data iritasi disajikan dalam bentuk tabel kemudian dianalisa secara deskriptif. Data $\mathrm{pH}$ dan viskositas selama masa penyimpanan 28 hari dan pada cycling test dianalisis secara statistik dengan menggunakan analisa uji $\mathrm{T}$ berpasangan untuk mengetahui perubahan $\mathrm{pH}$ dan viskositas sebelum dan sesudah penyimpanan dan akhir siklus pengujian.

\section{Hasil dan pembahasan}

Tumbuhan Dasimer (P. crocatum Ruiz \& Pav) diperoleh dari Desa Beringin Kecamatan Lubai Kabupaten Muara Enim. Proses pembuatan ekstrak dilakukan dengan menggunakan metode ekstraksi yaitu maserasi. Metode ini dipilih karena pengerjaannya yang mudah dan alat yang digunakan pun sederhana dan juga cocok untuk sampel yang tidak tahan terhadap pemanasan. Daun disortir, dicuci dan dikering-anginkan kemudian dihaluskan dan dimaserasi 
menggunakan etanol 70\%. Dari pengerjaan ekstraksi didapatkan ekstrak kental sebanyak 336 gram dan didapatkan persen rendemen $14,28 \%(\mathrm{~b} / \mathrm{b})$.

Dalam penelitian ini dilakukan formulasi sediaan losion deodoran dengan variasi konsentrasi asam stearat sebagai basis, dan zat aktif yang digunakan Dasimer (P. crocatum Ruiz \& Pav) sebagai antibakteri, alfa tokoferol sebagai antioksidan, setil alkohol sebagai emolient, trietonolamin sebagai emulgator, metil paraben sebagai pengawet, propil paraben sebagai pengawet, gliserin sebagai humektan, dan minyak esensial lemon sebagai pewangi.

Sediaan deodoran yang telah ditambahkan bahan-bahan tambahan dalam formula dengan variasi konsentrasi asam stearat sebagai basis mempengaruhi sifat fisik dari sediaan tersebut. Semakin tinggi konsentrasi asam stearat yang digunakan maka semakin baik bentuk sediaan yang dihasilkan (Ervianingsih \& Razak, 2019). Oleh karena itu, penggunaan asam stearat memiliki peran penting dalam pembuatan sediaan. Asam stearat dapat menghasilkan basis sediaan yang stabil serta membantu mengikat dan mengentalkan sediaan sehingga menghasilkan bentuk sediaan yang baik dan memiliki waktu simpan lebih lama (Safira \& Sari, 2014).

\subsection{Pemeriksaan organoleptis}

Hasil uji organoleptis sediaan losion deodoran dari ekstrak Dasimer dapat dilihat pada Tabel 2.

Tabel 2. Pengamatan organoleptis sediaan losion deodoran

\begin{tabular}{cccc}
\hline \multirow{2}{*}{ Formula } & \multicolumn{3}{c}{ Pemeriksaan organoleptis } \\
\cline { 2 - 4 } & Warna & Bau & Bentuk \\
\hline FI & CK & BK & SK \\
FII & CK & BK & SK \\
FIII & CK & BK & SK \\
\hline Keterangan : CK : Coklat Kekuningan & \\
& BK : Bau Khas & \\
& SK : Sedikit Kental &
\end{tabular}

Hasil pemeriksaan organoleptis menunjukkan bahwa penambahan ekstrak Dasimer $(P$. crocatum Ruiz \& Pav) pada FI, FII dan FIII menghasilkan warna dari ketiga formula sediaan losion deodoran menjadi coklat kekuningan, dengan bau khas dan ketiga formula sediaan tersebut memiliki bentuk sedikit kental. Ketiga formula sediaan tersebut menghasilkan sediaan yang stabil secara organoleptis selama masa penyimpanan 28 hari.

\subsection{Homogenitas}

Uji homogenitas sediaan losion deodoran dari ekstrak Dasimer sebagaimana tersaji pada Tabel 3. 
Tabel 3. Pengamatan homogenitas sediaan losion deodoran

\begin{tabular}{cccc}
\hline Hari ke- & FI & FII & FIII \\
\hline 0 & Homogen & Homogen & Homogen \\
7 & Homogen & Homogen & Homogen \\
14 & Homogen & Homogen & Homogen \\
21 & Homogen & Homogen & Homogen \\
28 & Homogen & Homogen & Homogen \\
\hline
\end{tabular}

Hasil pengujian homogenitas menunjukkan bahwa ketiga formula memiliki karakteristik yang homogen selama masa penyimpanan 28 hari. Sediaan disebut homogen jika pada saat pengujian tidak terdapat partikel-partikel kasar pada sediaan losion deodoran, serta warna tercampur secara merata.

\subsection{Pengujian $\mathrm{pH}$}

Pengujian pH sediaan losion deodoran dari ekstrak Dasimer sebagaimana tersaji pada Tabel 4 .

Tabel 4. Pengukuran $\mathrm{pH}$ sediaan losion deodoran

\begin{tabular}{cccc}
\hline \multirow{2}{*}{ Hari ke- } & \multicolumn{3}{c}{ Rata-rata pH \pm SD } \\
\cline { 2 - 4 } & FI & FII & FIII \\
\hline 0 & $6,4 \pm 0,05$ & $60 \pm 0,05$ & $5,8 \pm 0,10$ \\
7 & $6,3 \pm 0,10$ & $6,0 \pm 0,05$ & $5,7 \pm 0,05$ \\
14 & $6,2 \pm 0,05$ & $6,0 \pm 0,05$ & $5,6 \pm 0,05$ \\
21 & $6,1 \pm 0,05$ & $5,9 \pm 0,05$ & $5,5 \pm 0,10$ \\
28 & $6,0 \pm 0,05$ & $5,8 \pm 0,10$ & $5,5 \pm 0,05$ \\
\hline
\end{tabular}

Pemeriksaan pH sediaan losion deodoran ekstrak etanol Dasimer (P. crocatum Ruiz \& Pav) menggunakan alat pH meter (Tabel 4). Nilai pH dalam sediaan berada pada kisaran pH kulit yang sesuai dengan standar SNI dengan $\mathrm{pH}$ yaitu kisaran $\mathrm{pH}$ 4,5-8,0 agar tidak terjadi iritasi pada kulit. Bila pH sediaan berada di luar interval pH kulit dikhawatirkan akan menyebabkan terjadinya iritasi pada kulit sedangkan bila berada di atas pH kulit dapat menyebabkan kulit terasa cepat kering (Mardikasari dkk, 2017). Hasil pengamatan menunjukkanbahwa FI, FII dan FIII memasuki rentang $\mathrm{pH}$ sediaan deodoran. Hasil pH tertinggi dengan nilai rata-rata $\mathrm{pH}$ 6,4 dan nilai terendah 5,5. Untuk hasil uji T berpasangan untuk sediaan selama penyimpanan 28 hari menunjukkan bahwa pada FI dan FII ada perbedaan yang signifikan $(\mathrm{p}<0,05)$ antara $\mathrm{pH}$ sebelum dan sesudah penyimpanan sedangkan FIII nilai signifikansi $\mathrm{p} \geq 0,05$ yang berarti tidak ada perbedaan antara $\mathrm{pH}$ sebelum dan sesudah penyimpanan pada formula selama masa penyimpanan 28 hari. Hal ini menunjukkan bahwa FIII merupakan formula yang paling stabilnya pHnya. 


\subsection{Viskositas}

Uji viskositas sediaan losion deodoran dari ekstrak Dasimer sebagaimana tersaji pada Tabel 5.

Tabel 5. Pengukuran viskositas sediaan losion deodoran

\begin{tabular}{cccc}
\hline \multirow{2}{*}{ Hari ke- } & \multicolumn{3}{c}{ Rata-rata viskositas (cps) \pm SD } \\
\cline { 2 - 4 } & FI & FII & FIII \\
\hline 0 & $3316 \pm 76,37$ & $4733 \pm 125,83$ & $6083 \pm 354,72$ \\
7 & $3066 \pm 125,83$ & $4633 \pm 57,73$ & $6066 \pm 305,50$ \\
14 & $3066 \pm 208,16$ & $4566 \pm 251,66$ & $6016 \pm 325,32$ \\
21 & $3033 \pm 76,37$ & $4466 \pm 152,75$ & $5950 \pm 529.15$ \\
28 & $2550 \pm 150$ & $4266 \pm 236,29$ & $5773 \pm 57.73$ \\
\hline
\end{tabular}

Pengujian viskositas menunjukkan bahwa ketiga formula sebelum penyimpanan selama 28 hari mengalami peningkatan (Tabel 5). Hal ini disebabkan karena semakin tinggi konsentrasi asam stearat yang digunakan maka sediaan yang dihasilkan semakin kental dan viskositas yang dihasilkan nilainya tinggi.

Setelah penyimpanan sediaan selama 28 hari terjadi penurunan viskositas pada semua formula (Tabel 5). Penurunan viskositas yang terjadi kemungkinan disebabkan oleh menurunnya aktivitas alfa tokoferol yang berperan sebagai antioksidan pada sediaan, sehingga minyak dalam sediaan akan teroksidasi yang akan mengubah sifat minyak tersebut menjadi asam dan menyebabkan terjadinya penurunan viskositas sediaan (Mardikasari dkk, 2017). Meskipun pada pengujian viskositas dari ketiga formula mengalami penurunan akan tetapi ketiga formula tersebut masih memasuki rentang viskositas yaitu 2000-8000 (Cps) (Daud dkk, 2018). Berdasarkan uji T berpasangan FI, FII, dan FIII menunjukkan hasil bahwa FIII juga paling stabil viskositasnya karena hanya pada FIII tidak ada perbedaan yang signifikan sebelum dan sesudah penyimpanan selama 28 hari $(p \geq 0,05)$. Sedangkan pada FI dan FII menunjukkan perbedaan yang signifikan $(\mathrm{p} \leq 0,05)$ antara sebelum dan sesudah penyimpanan selama 28 hari yang mengindikasikan ketidakstabilan viskositas pada kedua formula tersebut.

\subsection{Daya sebar}

Pengujian daya sebar sediaan losion deodoran dapat dilihat pada Tabel 6.

Tabel 6. Pengukuran daya sebar sediaan losion deodoran

\begin{tabular}{cccc}
\hline \multirow{2}{*}{ Hari ke- } & \multicolumn{3}{c}{ Rata-rata daya sebar $(\mathrm{cm}) \pm$ SD } \\
\cline { 2 - 4 } & FI & FII & FIII \\
\hline 0 & $6,25 \pm 0,03$ & $5,87 \pm 0,03$ & $5,42 \pm 0,02$ \\
7 & $6,38 \pm 0,06$ & $5,95 \pm 0,03$ & $5,51 \pm 0,02$ \\
14 & $6,47 \pm 0,02$ & $5,99 \pm 0,01$ & $5,57 \pm 0,04$ \\
21 & $6,54 \pm 0,01$ & $6,09 \pm 0,05$ & $5,64 \pm 0,02$ \\
28 & $6,75 \pm 0,18$ & $6,16 \pm 0,03$ & $5,78 \pm 0,07$ \\
\hline
\end{tabular}


Pada pengujian daya sebar (Tabel 6), terlihat bahwa FI, FII dan FIII memiliki rentang daya sebar sediaan yang baik yaitu 5-7 $\mathrm{cm}$ dimana nilai penyebaran tertinggi 6,75 $\mathrm{cm}$ dan nilai terendah 5,42 $\mathrm{cm}$ selama penyimpanan 28 hari, sehingga dapat disimpulkan selama masa penyimpanan daya sebar sediaan stabil.

\subsection{Daya lekat}

Uji daya lekat sediaan losion deodoran dari ekstrak daun sirih tersaji pada Tabel 7.

Tabel 7. Pengukuran daya lekat losion deodoran

\begin{tabular}{cccc}
\hline \multicolumn{4}{c}{ Rata-rata daya lekat (detik) \pm SD } \\
\hline Hari ke- & FI & FII & FIII \\
\hline 0 & $4,16 \pm 0,01$ & $4,47 \pm 0,02$ & $5,28 \pm 0,03$ \\
7 & $4,13 \pm 0,01$ & $4,39 \pm 0,02$ & $5,20 \pm 0,03$ \\
14 & $4,09 \pm 0,01$ & $4,36 \pm 0,01$ & $5,02 \pm 0,03$ \\
21 & $4,04 \pm 0,03$ & $4,28 \pm 0,02$ & $4,88 \pm 0,09$ \\
28 & $4,02 \pm 0,02$ & $4,19 \pm 0,05$ & $4,60 \pm 0,09$ \\
\hline
\end{tabular}

Hasil pengujian daya lekat selama penyimpanan 28 hari mengalami penurunan pada ketiga formula (Tabel 7). Meskipun pada pengujian daya lekat dari ketiga formula mengalami penurunan akan tetapi pemeriksaan daya lekat menunjukkan bahwa sediaan losion deodoran ekstrak etanol Dasimer (Piper crocatum Ruiz \& Pav) dari ketiga formula tersebut memenuhi syarat uji daya lekat yaitu tidak kurang dari 4 detik (Megantara, dkk 2017).

\subsection{Cycling test}

Hasil uji stabilitas dengan metode cycling test pada $\mathrm{pH}$ dan viskositas tersaji pada Tabel 8 dan 9.

Tabel 8. Pengamatan cycling test $\mathrm{pH}$

\begin{tabular}{cccc}
\hline \multirow{2}{*}{ Siklus ke- } & \multicolumn{3}{c}{ Rata-rata cycliing test $\mathrm{pH} \pm$ SD } \\
\cline { 2 - 4 } & F I & FII & FIII \\
\hline 0 & $6,4 \pm 0,05$ & $6,0 \pm 0,05$ & $5,7 \pm 0,05$ \\
1 & $6,2 \pm 0,05$ & $5,9 \pm 0,05$ & $5,7 \pm 0,05$ \\
2 & $6,2 \pm 0,50$ & $5,9 \pm 0,05$ & $5,6 \pm 0,05$ \\
3 & $6,2 \pm 0,10$ & $5,8 \pm 0,05$ & $5,6 \pm 0,10$ \\
4 & $6,1 \pm 0,10$ & $5,8 \pm 0,10$ & $5,6 \pm 0,05$ \\
5 & $6,0 \pm 0.05$ & $5,8 \pm 0,10$ & $5,5 \pm 0,50$ \\
6 & $5,9 \pm 0,05$ & $5,7 \pm 0,05$ & $5,5 \pm 0,05$ \\
\hline
\end{tabular}

Pemeriksaan organoleptis setelah dilakukan cycling test selama penyimpanan 6 siklus pada ketiga formula memberikan hasil tidak terjadinya perubahan bentuk, bau dan warna. Hal ini menunjukan bahwa dari pengujian organoleptis semua formula dikatakan stabil. Pada pengujian pH berdasarkan cycling test (Tabel 8) didapatkan hasil penurunan nilai pH pada masing-masing formula sediaan selama penimpanan 6 siklus, namun penurunan yang 
signifikan terjadi pada FI dan FII $(\mathrm{p} \leq 0,05)$ sedangkan pada FIII tidak signifikan $(\mathrm{p} \leq 0,05)$. Hal ini menunjukkan bahwa FIII mempunyai stabilitas $\mathrm{pH}$ yang lebih bagus dibandingkan FI dan FII. Kestabilan pH selain dipengaruhi oleh formula, juga bisa dipengaruhi oleh kondisi penyimpanan yang berubah-ubah khususnya perubahan temperatur yaitu pada suhu rendah dan suhu tinggi dan kondisi lingkungan (Gozali dan Zaini, 2014).

Tabel 9. Pengamatan cycling test viskositas

\begin{tabular}{cccc}
\hline \multirow{2}{*}{ Siklus ke- } & \multicolumn{3}{c}{ Rata-rata viskositas(Cps) \pm SD } \\
\cline { 2 - 4 } & FI & FII & FIII \\
\hline 0 & $3166 \pm 104,08$ & $4766 \pm 76,37$ & $6300 \pm 132,28$ \\
1 & $3166 \pm 104,08$ & $4766 \pm 76,37$ & $6300 \pm 132,28$ \\
2 & $3000 \pm 100,00$ & $4433 \pm 76,37$ & $5950 \pm 50,00$ \\
3 & $2933 \pm 76,37$ & $4200 \pm 312,24$ & $5900 \pm 50,00$ \\
4 & $2750 \pm 86,60$ & $4150 \pm 200,00$ & $5816 \pm 125,83$ \\
5 & $2733 \pm 125,83$ & $3966 \pm 175,59$ & $5806 \pm 40,41$ \\
6 & $2583 \pm 28,86$ & $3516 \pm 425,24$ & $5900 \pm 100,00$ \\
\hline
\end{tabular}

Pada pengujian viskositas berdasarkan cycling test didapatkan hasil bahwa terjadi penurunan viskositas sediaan losion deodoran pada masing-masing formula (Tabel 9). Namun berdasarkan uji T-berpasangan, ternyata di antara ketiga formula, FIII mengalami perubahan yang signifikan yakni p 0,094 ( $\mathrm{p} \leq 0,05)$ pada siklus cycling test. Hal ini menunjukkan bahwa FIII paling tidak stabil viskositasnya dibandingkan dengan FI dan FII.

\subsection{Uji iritasi}

Uji iritasi sediaan losion deodoran ekstrak Dasimer tersaji Tabel 10

Tabel 10. Pengamatan iritasi losion deodoran

\begin{tabular}{cccc}
\hline Panelis & FI & FII & FIII \\
\hline 1 & - & - & - \\
2 & - & - & - \\
3 & - & - & - \\
4 & - & - & - \\
5 & - & - & - \\
6 & - & - & - \\
7 & - & - & - \\
8 & - & - & - \\
9 & - & - & - \\
10 & - & - & - \\
\hline Keterangan : & + & :Terjadi Iritasi &
\end{tabular}

Data Tabel 8 menunjukkan bahwa sediaan losion deodoran ekstrak Dasimer aman dan tidak mengiritasi pada kulit sukarelawan. Dari hasil uji iritasi yang diakukan terhadap 10 sukarelawan untuk ketiga formula didapatkan hasil bahwa ketiga formula terebut tidak menyebabkan iritasi kulit seperti kemerahan dan bengkak serta gatal pada kulit (Tabel 10). Hal 
ini menunjukkan bahwa ketiga formula sediaan deodoran tersebut dinyatakan aman untuk digunakan.

\section{Kesimpulan}

Berdasarkan hasil pemeriksaan sediaan losion deodoran ekstrak Dasimer (P. crocatum Ruiz \& Pav) dengan variasi asam stearat sebagai basis maka didapatkan kesimpulan dari ketiga formula losion deodoran ekstrak etanol Dasimer (P. crocatum Ruiz \& Pav) 7,5\%, formula yang paling baik dan stabil yaitu FIII dengan konsentrasi asam stearat 6\%.

\section{Daftar Pustaka}

Agoes,G. (2015).Sediaan Kosmetik (SF1-9). Bandung : Institut Teknologi Bandung.

Candrasari, A., Romas., M.A., Hasbi., M dan Astuti, O.R. (2012).Uji Daya Antimikroba Ekstrak Etanol Daun Sirih Merah (Piper crocatum Ruits \& Pav) Terhadap Pertumbuhan Staphylococcus aureus ATCC 6538, Eschericia coli ATCC 11229 Dan Candida albicans ATCC 10231 Secara In vitro.Jurnal Biomedika, 4 (1) : 9-16.

Daud, N. S., Musdalipah., dan Idayati. (2018).Optimasi Formula Lotion Tabir Surya Ekstrak Kulit Buah Naga Super Merah (Hylocereus costariensis) Menggunakan Metode Desain DOptimal.Jurnal Sains Farmasi \& Klinis.4 (2) : 72-77.

Ervianingsi dan Razak., A. (2019). Formulasi Sediaan Deodoran Lotion Dari Minyak Atsiri Nilam (Pogostemon cablin Benth).Jurnal Fenomena Kesehatan, 2 (1) : 188-196.

Gozali, D., dan Zaini , A.N. (2014). Pengaruh Suhu Terhadap Stabilitas Obat sediaan Suspensi.Farmaka, 14 (2): 1-6.

Lailiyah, M., Sukmana, P.H., Yudha, E. (2019).Formulasi Deodora Roll On Ekstrak Daun Waru (Hiiscus tiliaceus) Pada Konsentraasi 3\%; 5\%; 8\% Dan Uji Aktivitas Terhadap Bakteri Staphylococcus aureus. Chendekia Journal of Pharmacy, 3 (2) : 106-114.

Mardikasari, S.A., Mallarangeng, A.N., Zubaydah, W.O. (2017). Formulasi dan Uji Stabilitas Lotion dari Ekstrak Daun Jambu Biji (Psidium guajava L.) Sebagai Antioksidan. Jurnal Farmasi, Sains, dan Kesehatan, 3 (2): 28-32.

Megantara, I.N., Megayanti, K., Wirayanti, R., Esa, I.B., Wijayanti, N.P., Yustiantara, P.S. (2017). Formulasi Lotion Ekstrak Buah Raspberry (Rubus rosifolius) dengan Variasi Konsentrasi Trietanolamin sebagai Emulgator Serta Uji Hedonik Terhadap Lotion.Jurnal Farmasi Udayana, 6 (1) : 1-5.

Menkes RI. (2010). Peraturan Menteri Kesehatan RI No.1176 Tentang Notifikasi Kosmetika.Jakarta : Menteri Kesehatan RI.

Safira, D., dan Sari, D. (2014). Pengaruh Konsentrasi Asam Stearat Terhadap Karakteristik Sediaan Dan Pelepasan Krim Kurkumin. Jurnaal Pharmascience. 4 (1) : 14-17.

Sari, E. P. (2019).Formulasi Sediaan Deodorant Stick Dari Ekstrak Daun Mangkokan (Nothopanax scutellarium Merr) Dan Uji Kestabilan Fisiknya.KTI. Politeknik Kesehatan, Palembang.

Timur, Willi, W., Fadzil, L. (2019). Formulasi Sediaan Deodoran dalam bentuk krim menggunakan Kombinasi Aluminium Sulfat dan Minyak Kayu Cendan.Ad-Dawaa Journal of Pharmaceutical Science,2 (1), 6-15.

Umami, Z. (2019). Formulasi dan Evaluasi Sabun Cair Ekstrak Daun Sirih Merah (Piper crocatum Riuts \& Pav) Serta Uji Aktivitas Sebagai Antiseptik Terhadap Bakteri Staphylococcus aureus.Skripsi. Institut Kesehatan Helvetia, Medan.

Seminar Nasional Asosiasi Perguruan Tinggi Farmasi Indonesia (APTFI) III-Tantangan Pandemik (covid-19) dalam pembelajaran dan penelitian kefarmasian 16-20 Agustus 2021 (Virtual Conference) 
168 | Lidia, dkk /Jurnal Ilmiah Farmasi (Scientific Journal of Pharmacy) Special Edition 2022, 159-168

Wasitaatdmaja, S. (1997).Penuntun Ilmu Kosmetik Medis. Jakarta : Universitas Indonesia press. Zulkarnain, A.K., Susanti, M. dan Lathifa, N. (2013). The Physical Stability of lotion O/W and W/O from Phaleria macrocarpa Fruit Extract As Sunscreen and Primary Irritation Test on Rabbit.Traditional Medicine Journal, 18 (3): 141-150 